\title{
EFSUMB Honorary Members
}

EFSUMB is pleased to announce the election of Prof Luigi Bolondi, Bologna, Italy as an Honorary Member, for his major contribution to the field of ultrasound.

Luigi Bolondi has pioneered the development of clinical ultrasonography in Europe and worldwide. He became involved in this new technique in his late medical school years in 1972/3. He rapidly developed and led the new emerging imaging technology and wrote textbooks in abdominal ultrasound based on his personal experience and discoveries in the late 70 s', which have been the reference to learn ultrasound for many Italian and European physicians. He has been a visiting fellow at Prof. Holm's laboratory in Copenhagen and following this was among the first ones to report on the possibility to perform ultrasound guided liver and pancreas interventions and particularly US guided biopsy and percutaneous ethanol injection for small HCC. He published several works in the field of applications of ultrasound in liver disease, including the diagnosis of Budd Chiari syndrome, the abnormalities occurring in the instance of portal hypertension and the diagnostic patterns and treatment modalities of

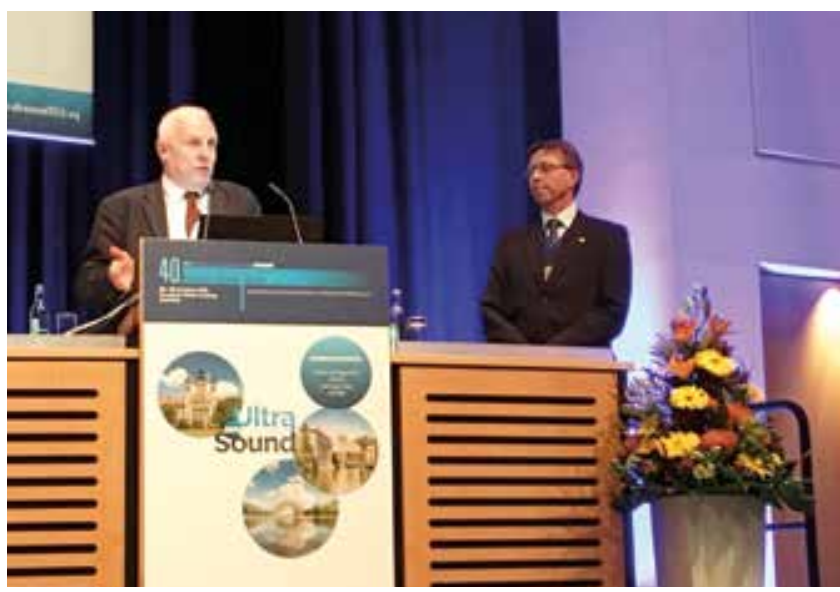

Prof Luigi Bolondi EFSUMB's newest Honorary Member. 
(over 2400 attendees from more than 40 Countries) and the EUROSON congresses in Bologna in 1978 and in 2006.

As EFSUMB President he paid great attention to the promotion of countries from the former Soviet Union, facilitating the training and participation of their members to European initiatives. Those countries which in many instances had become independent only for a relative short time are now very active and relevant contributors to EFSUMB. He also promoted the change in the EUROSON congress organization from a self standing event to an event to be run in conjunction with one National Society at a time during its national congress, revitalizing the congresses, in a modality which is still successfully adopted today.

Written by Stefania Speca, President SIUMB 2016 